ORIGINAL ARTICLE

\title{
Determine the Clinical Presentation and Outcomes of Thoracostomy in Children with Complicated Pneumonia
}

SHAFIQ-UR-REHMAN ${ }^{1}$, SANAULLAH KHAN $^{2}$, MUHAMMAD ANWAR ${ }^{3}$, ARSHAD RAFIQUE4 ZAFAR IQAL BHATTI5 SHAZIA SIDDIQUE 6

${ }^{1}$ Associate Professor of Paediatric Surgery, Sahiwal Medical College Sahiwal

${ }^{2}$ Assistant Professor of Paediatrics, Rashid Latif Medical College, Lahore

${ }^{3}$ Associate Professor of Paediatrics, Rashid Latif Medical College, Lahore

${ }^{4}$ Associate Professor of Paediatrics, Avicenna Medical College Lahore

5 Associate Professor of Paediatrics, Central Park Medical College, Lahore

6Assitant Professor of Medicine, Fatima Jinnah Medical University, Lahore

Correspondence to: Dr. Shafiq-ur-Rehman, E-mail: shafiqlangriyal@gmail.com, Cell: 0300-9695031

\begin{abstract}
Objective: To examine the clinical presentation and outcomes of thoracostomy in patients presented with complicated pneumonia.

Study Design: Descriptive/Observational

Place and Duration of Study: Department of Paediatric Surgery, DHQ Teaching Hospital Sahiwal from $1^{\text {st }}$ January 2019 to $31^{\text {st }}$ December 2020.

Methodology: Fifty patients of both genders with ages 0 to 12 years presented with complicated pneumonia were included. All the patients received chest tube intubation. Outcomes of thoracostomy were examined. Radiological examination was done.

Results: Thirty eight (76\%) patients were males while $24 \%$ were females. Majority of patients $64 \%$ were ages less than 5 years. Fever, cough, shortness of breath and chest pain were the common symptoms. Staphylococcus aureus was the most common causative factor found in $56 \%$ cases followed by streptococcus in $24 \%$ cases. $84 \%$ cases were successfully removed chest tube. Recollection found in $8 \%$ cases, pneumothorax found in $4 \%$ patients and $4 \%$ patients had pneumatocele.

Conclusion: Chest tube intubation was the safe and effective treatment modality for complicated pneumonia with fewer rates of complications.

Keywords: Complicated pneumonia, Thoracostomy, Empyema, Pneumothorax, Outcomes
\end{abstract}

\section{INTRODUCTION}

Complicated pneumonia is defined in the pleural cavity as the collection of pus. ${ }^{1}$ It is a life-threatening condition common in paediatric patients. Hippocrates was the first person to diagnose this ailment more than 2000 years ago through the drainage of the pleural cavity. ${ }^{2}$ It is caused most frequently by staphylococci and less often by hemophilus influenzae. It may occur as a result of trauma, lung abscess rupture or primary tuberculosis complication. ET is usually caused related to bacterial pneumonia in youngsters. The highest incidence of pneumonia in children under 5 years of age is and a higher proportion of hospital admission in children is responsible for pneumonia. ${ }^{3}$ About $0.6 \%$ of pneumonia leads to empyema thorax formation. ${ }^{4,5}$ The incidence of this disease is continuing to increase in both developed and developing countries in the recent antibiotic age and represents a serious burden on society. Day by day, empyema increases the high morbidity and mortality rate among children. This could be caused to poverty, carelessness, malnutrition or resistance to many medicines. ${ }^{6-8}$ The most common surgical technique in thoracic surgery is thoracostomy tube. As a life-saving treatment, general surgeons, emergency physicians and respiratory doctors may be required to conduct thoracostomy of the tube at some time. ${ }^{9}$

Tube thoracostomy is an invasive treatment and difficulties can emerge from insufficient thoracic anatomy knowledge or poor training and expertise. These difficulties can be characterized simply as technical or infectious. Trocar technology is, by far, linked to a higher complication rate. ${ }^{10}$ The present study was conducted to examine the clinical presentation and outcomes of thoracostomy in children with complicated pneumonia.

\section{MATERIALS AND METHODS}

This descriptive study was conducted at Department of Paediatric Surgery, DHQ Teaching Hospital Sahiwal from $1^{\text {st }}$ January 2019 to $31^{\text {st }}$ December 2020. A total of 50 patients of both genders with ages 0 to 12 years presented with complicated pneumonia were included. Patients detailed demographic including age, sex and symptoms of disease were recorded after taking written consent from parents/guardian. Patients with congenital pulmonary disease, cardiac disease, post surgical and post traumatic patients of empyema were excluded.

The patients with pleural effusions more than $10 \mathrm{~mm}$ on ultrasound or opacities occupying more than half of hemithorax on X-ray were included. Pleural fluid and blood culture was examined to observe the growth of microorganism. All the patients were received chest tube insertion according to the British Thoracic society guidelines by drawing triangle of safety. Reducing the amount of pleural fluid on ultrasound or X-ray was considered successful outcomes. Complications associated to chest tube insertion were examined. Patients were followed till than the full recovery. Data was analyzed by SPSS 24.

RESULTS

There were 38 (76\%) male patients while $12(24 \%)$ were 
females. Majority of patients $64 \%$ were ages less than 5 years. Twelve (24\%) patients had ages 6 to 10 years and 6 $(12 \%)$ patients were ages above 10 years. Fifty (100\%) patients had fever, $72 \%$ patients had cough, shortness of breath found in $60 \%$ patients, $44 \%$ patients had chest pain, $16 \%$ patients had vomiting and $8 \%$ patients with abdominal pain. $100 \%$ patients intercostals tenderness, $86 \%$ patients had tachypnea and $84 \%$ patients had diminished chest movement. Mostly patients $72 \%$ patients had simple pleural effusion, $10(20 \%)$ patients had empyema and 4 (8\%) patients had pneumothorax (Table 1).

Staphylococcus aureus was the most common causative factor found in $56 \%$ cases followed by streptococcus in $24 \%$ cases, $4(8 \%)$ patients had Klebsiella pneumoniae, $3(6 \%)$ patients had Pseudomonas aeruginosa and $3(6 \%)$ patients had mycobacterium tuberculosis (Table 2). The outcomes of chest tube insertion, we found $84 \%$ cases were successfully removed chest tube while recollection found in $8 \%$ cases, pneumothorax found in $4 \%$ patients and $4 \%$ patients had pneumatocele (Table 3).

Table 1: Demographic details of the patients

\begin{tabular}{|l|l|l|}
\hline Variable & No. & $\%$ \\
\hline Gender & 38 & 76.0 \\
\hline Male & 12 & 24.0 \\
\hline Female & 32 & 64.0 \\
\hline Age (years) & 12 & 24.0 \\
\hline$<5$ & 6 & 12.0 \\
\hline $6-10$ & 50 & 100.0 \\
\hline$>10$ & 36 & 72.0 \\
\hline Symptoms & 30 & 60.0 \\
\hline Fever & 22 & 44.0 \\
\hline Cough & 8 & 16.0 \\
\hline Breath shortness & 4 & 8.0 \\
\hline Chest Pain & \multicolumn{2}{|l|}{} \\
\hline Vomiting & 36 & 72.0 \\
\hline Abdominal pain & 10 & 20.0 \\
\hline Indications of complicated pneumonia & 4 & 8.0 \\
\hline Simple pleural effusion & 4 \\
\hline Empyema & \multicolumn{2}{|l|}{} \\
\hline Pneumothorax &
\end{tabular}

Table 2: Culture results of microorganism among all the patients

\begin{tabular}{|l|l|l|}
\hline Variable & No. & $\%$ \\
\hline Staphylococcus aureus & 28 & 56.0 \\
\hline Streptococcus & 12 & 24.0 \\
\hline Klebsiella pneumonia & 4 & 8.0 \\
\hline Pseudomonas aeruginosa & 3 & 6.0 \\
\hline Mycobacterium TB & 3 & 6.0 \\
\hline
\end{tabular}

Table 3: Final outcomes of thoracostomy

\begin{tabular}{|l|l|l|}
\hline Variable & No. & $\%$ \\
\hline Recovered & 42 & 84.0 \\
\hline Recollection & 4 & 8.0 \\
\hline Pneumothorax & 2 & 4.0 \\
\hline Pneumatocele & 2 & 4.0 \\
\hline
\end{tabular}

\section{DISCUSSION}

Pneumonia is one of the most common life threatening diseases in children with high rate of mortality and morbidity. In developing countries like Pakistan, the incidence rate of complicated pneumonia is quite high as compared to developed countries and children with ages 0 to 5 years were on high risk for developing complicated pneumonia. ${ }^{11,12}$ The present study was conducted to examine the clinical profile of complicated pneumonia in patients requiring thoracostomy. In this study 38 (76\%) patients were males while $24 \%$ were females. Majority of patients $64 \%$ were ages less than 5 years. $12(24 \%)$ patients had ages 6 to 10 years and $6(12 \%)$ patients were ages above 10 years. These results showed similarity to several previous studies in which male patients were predominant $70-85 \%$ as compared to females and the most common age group was 0 to 5 years. ${ }^{13,14}$

In the present study, fever was the commonly observed symptom among all the patients $100 \%$ followed by cough, breath shortness, chest pain and vomiting. We found that $100 \%$ patients intercostals tenderness, $86 \%$ patients had tachypnea and $84 \%$ patients had diminished chest movement. These results were similar to the study conducted by Meher et $\mathrm{al}^{15}$ regarding clinical presentation and management of empyema in children. They reported that fever was the commonest symptoms in $100 \%$ cases followed by cough, breath shortness and chest pain. Majority of patients had diminished chest movement.

In the current study, Staphylococcus aureus was the most common causative factor found in $56 \%$ cases followed by Streptococcus in $24 \%$ cases, 4 (8\%) patients had Klebsiella pneumoniae, $3(6 \%)$ patients had Pseudomonas aeruginosa and $3(6 \%)$ patients had mycobacterium tuberculosis. These results were similar to many of previous studies in which Staphylococcus aureus was the commonest causing factor accounted $60-75 \%$ in complicated pneumonia patients followed by streptococcus and Klebsiella pneumonia. ${ }^{16,17}$

This study showed that outcomes of chest tube insertion, we found $84 \%$ cases were successfully removed chest tube while recollection found in $8 \%$ cases, pneumothorax found in $4 \%$ patients and $4 \%$ patients had pneumatocele. Patients with recollection were received chest intubation again and followed till successful removal. A study conducted by Waris et $\mathrm{al}^{18}$ reported $80 \%$ patients had successfully removal of chest tube while $8.6 \%$ patients had recollection $5.6 \%$ patients had pneumothorax and $5.6 \%$ patients had pneumatocele.

\section{CONCLUSION}

The chest tube insertion was the safe and effective treatment modality for complicated pneumonia with fewer rates of adverse outcomes. The early and accurate diagnosis and proper management may helps to reduce the morbidity and mortality associated to complicated pneumonia.

\section{REFERENCES}

1. Light RW, Rodriguez RM. Management of parapneumonic effusions. Clin Chest Med 1998; 19:373-82.

2. Adams F. The Genuine works of hippocrates. Baltimore: William \& Wilkins Company; 1939; 512.

3. Rudan I, Tomaskovic L, Boschi-Pinto C, Campbell H, WHO Child Health Epidemiology Reference Group. Global estimate of the incidence of clinical pneumonia among children under five years of age. Bull World Health Organ 2004;82:895-903.

4. Byington CL, Spencer LY, Johnson TA, Pavia AT, Allen D, Mason EO, et al. An epidemiological investigation of a 
sustained high rate of pediatric parapneumonic empyema: Risk factors and microbiological associations. Clin Infect Dis 2002;34:434-40.

5. Schultz KD, Fan LL, Pinsky J, Ochoa L, Smith EO, Kaplan $\mathrm{SL}$, et al. The changing face of pleural empyemas in children: Epidemiology and management. Pediatrics 2004;113:1735-40.

6. Grijalva CG, Zhu Y, Nuorti JP, Griffin MR. Emergence of parapneumonic empyema in the USA. Thorax 2011;66:6638.

7. Dalavi SB, Gurav PD, Dalavi VS. Empyema thoracis in children; Aprospective study in rural India. Int J Rec Trend Sci Technol 2016; 18:144-8.

8. Saleem AF, Shaikh AS, Khan RS, Khan F, Faruque AV, Khan MA. Empyema thoracis in children; clinical presentation, management and complications. J Coll Physicians Surg Pak 2014;24:573-6.

9. Carter E, Waldhausen J, Zhang W, Hoffman L, Redding G. Management of children with empyema: Pleural drainage is not always necessary. Pediatr Pulmonol 2010;45:475-80.

10. Olarte L, Barson WJ, Barson RM, Romero JR, Bradley JS Tan TQ, et al. Pneumococcal Pneumonia Requiring hospitalization in US children in the 13-valent pneumococcal conjugate vaccine era. Clin Infect Dis 2017; 64(12):16991704.

11. Davis TR, Evans HR, Murtas J, Weisman A, Francis JL, Khan A. Utility of blood cultures in children admitted to hospital with community-acquired pneumonia. J Paediatr Child Health 2017; 53(3):232-6.
12. Keren R, Shah SS, Srivastava R, Rangel S, Bendel-Stenzel M, Harik N, et al. Pediatric Research in Inpatient Settings Network. Comparative effectiveness of intravenous vs oral antibiotics for postdischarge treatment of acute osteomyelitis in children. JAMA Pediatr 2015;169(2):120-8.

13. Hassan $M$, Cargill $T$, Harriss $E$, Asciak $R$, Mercer RM, Bedawi EO, et al. The microbiology of pleural infection in adults: a systematic review. Eur Respir J 2019; 54(3): 1900542.

14. Park S, Jo KW, Lee SD, Kim WS, Shim TS. Clinical characteristics and treatment outcomes of pleural effusions in patients with nontuberculous mycobacterial disease. Respir Med 2017; 133:36-41.

15. Meher SK, Mahapatra SK, Murmu SK, Meher P. Evaluation of predisposing factors, etiology, and clinical manifestations of childhood empyema thoracic at a tertiary care center of Odisha. Indian J Child Health 2018; 5(4):305-7.

16. Shen KR, Bribriesco A, Crabtree T, Denlinger C, Eby J, Eiken $\mathrm{P}$, et al. The American Association for Thoracic Surgery consensus guidelines for the management of empyema. J Thorac Cardiovasc Surg 2017; 153(6):e129-46.

17. Svigals PZ, Chopra A, Ravenel JG, Nietert PJ, Huggins JT. The accuracy of pleural ultrasonography in diagnosing complicated parapneumonic pleural effusions. Thorax 2017; 72(1):94-5.

18. Waris R, Riaz R, Raza SH, Akhtar S. Clinical profile and outcomes of complicated pneumonia. Pak Pediatr $\mathrm{J}$ 2019;43(3). 164-8. 